\title{
Mineralization and degradation of 4-Nitrophenol using homogeneous Fenton oxidation process
}

\author{
Minz Sudha, Gupta Renu', Garg Sangeeta \\ Department of Chemical Engineering, Dr. B. R. Ambedkar National Institute of Technology, Jalandhar-144011, Punjab, India
}

\begin{abstract}
The mineralization analysis of wastewater is important for the growth of flora and fauna. The mineralization along with the degradation of 4-NP has been studied using homogeneous Fenton oxidation process. The mineralization of 4-NP has been reported in terms of chemical oxygen demand (COD) removal $\%$ and total organic carbon (TOC) removal $\%$. The main parameters that affect the mineralization and degradation of 4-NP i.e. initial $\mathrm{pH}(1-5)$, reaction time $(0-60 \mathrm{~min})$, the concentration of hydrogen peroxide $(1-5 \mathrm{mM})$ and concentration of ferrous ions $(0.05-0.5 \mathrm{mM})$ have been optimized. In the present study, optimum reaction conditions for mineralization and degradation of 4-NP are observed at $\mathrm{pH} \mathrm{3,4} \mathrm{mM}$ of $\mathrm{H}_{2} \mathrm{O}_{2}$ concentration, $0.2 \mathrm{mM}$ of $\mathrm{Fe}^{2+}$ concentration and in $40 \mathrm{~min}$ of reaction time. At the optimum condition, $\mathrm{COD}$ removal and TOC removal were $50 \%$ and $60.3 \%$, respectively along with $93.6 \%$ of 4-NP degradation. At optimized conditions, intermediate products obtained after homogeneous degradation of 4-NP were identified based on LC-MS spectra analysis. The degradation of 4-NP followed, second order reaction rate. The present study showed the higher degradation and mineralization of 4-NP as compared to available studies on 4-NP.
\end{abstract}

Keywords: Chemical oxygen demand, Degradation, 4-Nitrophenol, Mineralization, Total organic carbon

\section{Introduction}

4-Nitrophenol (4-NP) is a hazardous, bio-refractory organic compound and is widely used for the production of pesticides, herbicides, insecticides and synthetic dyes [1]. It is highly stable and soluble in water and persists in soil and ground water for a longer period of time [2]. The discharge of 4-NP from various industries to water streams is of main concern due to its toxicity and suspected carcinogenicity. The development of efficient methods for removal of 4-NP, is becoming an important field of study for researchers.

Several treatment methods such as chemical, physical and biological have been employed for the treatment of 4-NP from wastewater [3]. Physical and biological treatment techniques are not very satisfactory as they transfer the pollutants from one phase to another, and the equipment required for these processes is also very costly [4]. Recently advanced oxidation processes (AOPs) showed considerable potential for the removal of 4-NP from industrial effluents [5-9]. In AOPs, the hydroxyl radicals ( $\left.{ }^{\circ} \mathrm{OH}\right)$ are generated in solution and are responsible for the oxidation and mineralization of the organic pollutants to water and carbon dioxide [10-13]. Among various AOPs, the Fenton oxidation process has

This is an Open Access article distributed under the terms of the Creative Commons Attribution Non-Commercial License (http://creativecommons.org/licenses/by-nc/3.0/) which permits unrestricted non-commercial use, distribution, and reproduction in any medium, provided the original work is properly cited.

Copyright (C) 2021 Korean Society of Environmental Engineers been used extensively, as reagents (ferrous sulphate heptahydrate and hydrogen peroxide) used are easy to handle and environmental friendly [14]. The main advantage of this method is that the reaction takes place at ambient temperature, atmospheric pressure and short reaction period, which makes the process less expensive [15].

Various studies available on degradation of organic pollutants using a homogeneous Fenton oxidation process are presented in Table 1.

It is observed from Table 1, that the homogeneous Fenton oxidation process is still very active for the degradation of various organic pollutants. Further, it is observed that most of the studies are available on the degradation/ decolourization of organic pollutants, however, very few studies are reported on mineralization (TOC and COD removal) of the organic pollutants. The studies of Fathi and Keshmirizadeh [4], Ertugay and Acar [16], Giri and Golder [17] and Barbusinski [18] have analyzed COD removal $\%$ for various organic pollutants. Giri and Golder [17] has reported TOC removal (37.9\%) for ciprofloxacin. The degradation studies alone do not reveal the conversion of toxic organic pollutants in simpler organic compounds. Thus mineralization of organic pollutants

Received April 11, 2019 Accepted May 27, 2020

${ }^{\dagger}$ Corresponding author

Email: bansalr@nitj.ac.in

Tel: +08283022833

ORCID: 0000-0002-9730-3969 


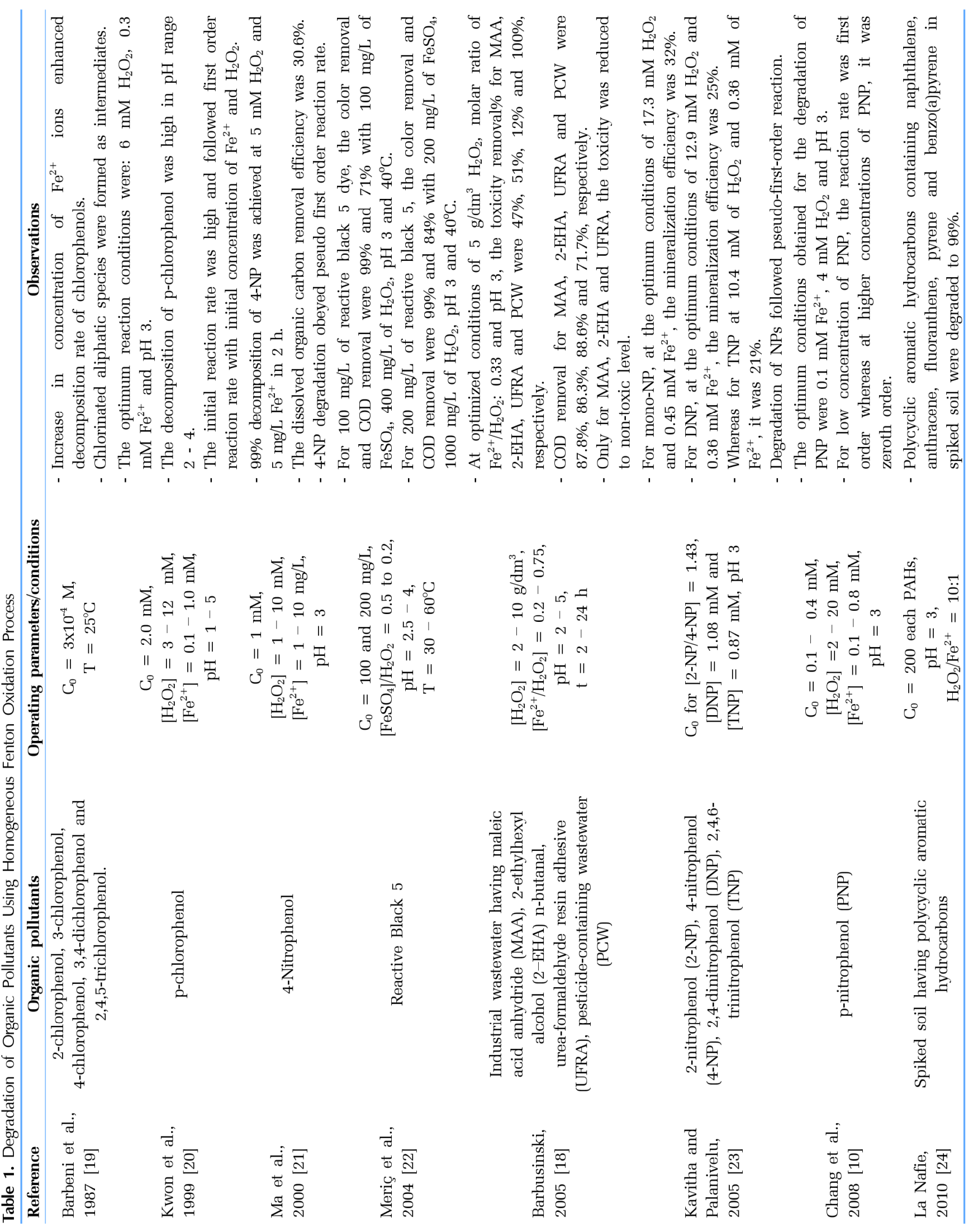




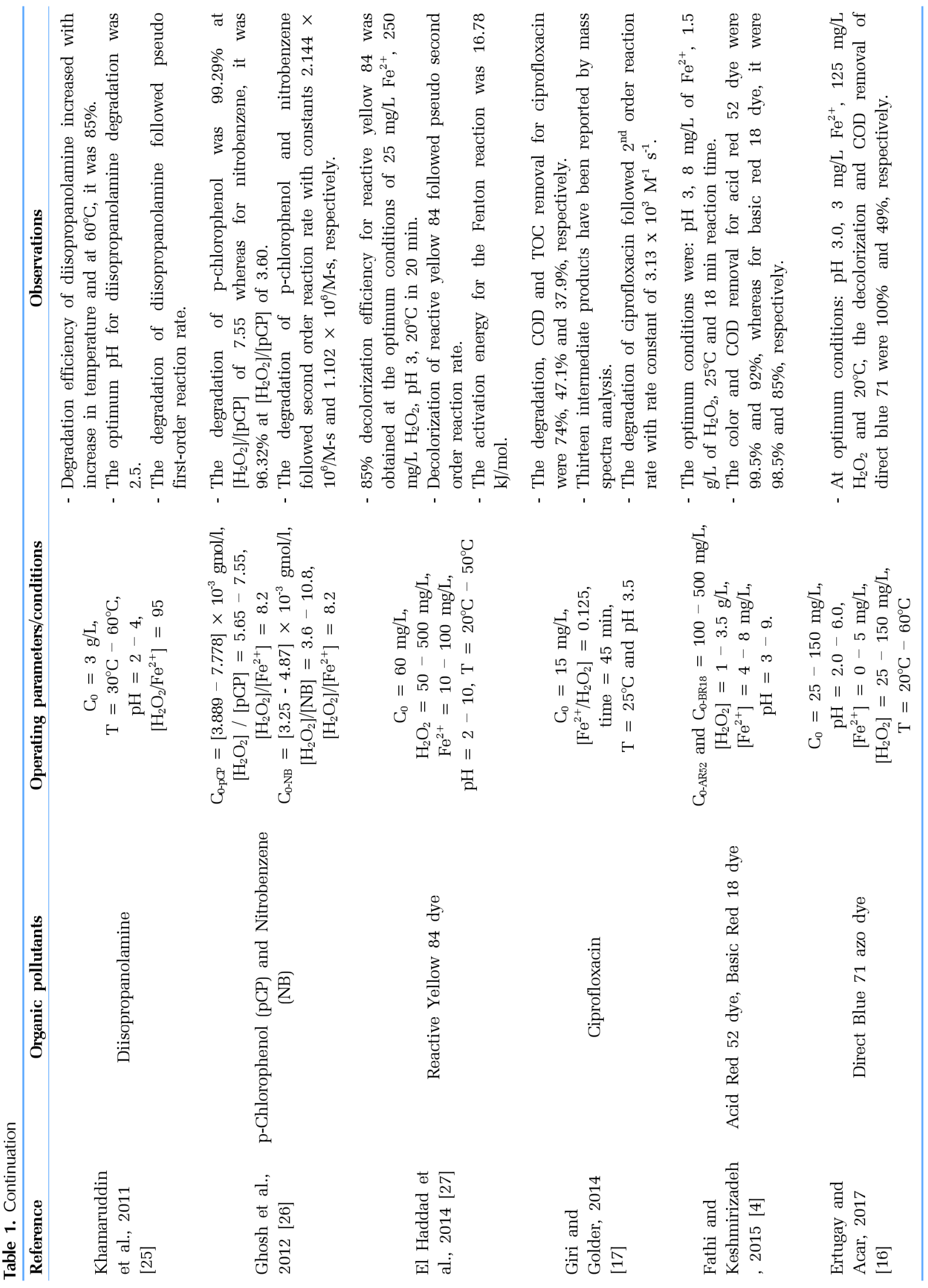


(TOC removal \% and COD removal \%) is also important along with decolorization/degradation studies and there is a need to study the mineralization of organic pollutants along with the degradation of organic pollutants.

The present study has been focused on mineralization of 4-NP along with its degradation using homogeneous Fenton oxidation process. Various parameters like initial $\mathrm{pH}$, reaction time, concentration of hydrogen peroxide and ferrous ions that affect the degradation and mineralization (COD and TOC removal \%) of 4-NP have been optimized. Further the studies have been extended to identify the degradation products of 4-NP using LC-MS spectra technique. The results of mineralization and degradation of 4-NP have also been compared with the available studies.

\section{Material and Methods}

\subsection{Materials}

4-NP (w/w, 98\% purity), ferrous sulphate heptahydrate $\left(\mathrm{FeSO}_{4} .7 \mathrm{H}_{2} \mathrm{O}\right)$ (w/w, purity $>99 \%$ ), sulphuric acid (98\% purity), mercuric sulphate (purity 99\%), silver sulphate (purity > 99\%), were obtained from Loba Chemie Pvt. Ltd. (Mumbai, India). Hydrogen peroxide (30\% w/w) was purchased from Ranbaxy Fine Chemicals Limited (Gujarat, India). Sodium hydroxide ( $\mathrm{NaOH}, 97 \%$ purity), ferrous ammonium sulphate (FAS) (99\% purity) was taken from s.d. fine Chemical Limited (Mumbai, India). Potassium dichromate $\left(\mathrm{K}_{2} \mathrm{Cr}_{2} \mathrm{O}_{7}\right.$, purity $>$ 99\%) was obtained from Qualigens Fine Chemicals (Mumbai, India). All the solutions were prepared using double distilled water.

\subsection{Experimental Procedure}

Batch experiments for mineralization and degradation of 4-NP were performed by taking $0.05 \mathrm{mM}$ ferrous sulphate solution into a $250 \mathrm{~mL}$ Erlenmeyer glass flask containing $100 \mathrm{~mL}$ of 4-NP (100 $\mathrm{mg} / \mathrm{L})$ solution. The $\mathrm{pH}$ of the solution was adjusted by the addition of a few drops of $\mathrm{H}_{2} \mathrm{SO}_{4}(0.1 \mathrm{~N})$ and $\mathrm{NaOH}(0.1 \mathrm{~N})$ and was measured using a $\mathrm{pH}$ meter ( $\mathrm{pH} 700$ Eutech). After the $\mathrm{pH}$ adjustment, 1 $\mathrm{mM} \mathrm{H}_{2} \mathrm{O}_{2}$ was added quickly to the solution with continuous stirring at $30^{\circ} \mathrm{C}$. With the addition of $\mathrm{H}_{2} \mathrm{O}_{2}$ solution, the reaction started and the samples were taken out from the flask periodically and the reaction was stopped by adding two drops of $1 \mathrm{M} \mathrm{NaOH}$. Thereafter, the solution was filtered and the filtrate was analyzed for mineralization (TOC and COD removal \%) and percentage degradation. The above experiments were repeated to study the effect of various parameters such as: $\mathrm{pH}(1-5)$, reaction time (0 - $60 \mathrm{~min})$, concentration of ferrous ions $(0.05-0.5 \mathrm{mM})$ and concentration of $\mathrm{H}_{2} \mathrm{O}_{2}(1-5 \mathrm{mM})$. All the experiments were repeated three times to get reproducibility of $\pm 5 \%$.

\subsection{Analytical Methods}

The 4-NP degradation (\%) after the reaction was analyzed using UV/VIS spectrophotometer at $\lambda_{\max } 318 \mathrm{~nm}$ (Shimadzu double beam spectrophotometer Model: UV-VIS 2600/2700). The degradation efficiency was calculated as:

$$
\text { Degradation efficiency }(\%)=\left(1-\frac{C_{t}}{C_{0}}\right) \times 100
$$

Where, $\mathrm{C}_{0}$ is the initial concentration, $\mathrm{C}_{t}$ is the concentration at any time $\mathrm{t}$.

The mineralization studies, chemical oxygen demand (removal $\%$ ) and total organic carbon (removal \%) were also analyzed after reaction. The COD of the samples before and after the reaction, was analyzed with MAC COD digester (Model: COD-439, Karnal, India) using a standard APHA method [28]. The COD efficiency of 4-NP was calculated as:

$$
\text { COD removal }(\%)=\left(1-\frac{\mathrm{COD}_{\mathrm{t}}}{\mathrm{COD}_{0}}\right) \times 100
$$

Where, $\mathrm{COD}_{\mathrm{t}}$ concentration at any time $\mathrm{t}$, and $\mathrm{COD}_{0}$ is initial concentration at time zero.

The TOC analysis of the samples was done using a TOC analyser (Model: ASI-V and TOC-V CPN, Shimadzu, Japan) before and after the degradation of 4-NP. The non-dispersive infrared method was adopted for the detection of TOC. The TOC efficiency was calculated as:

$$
\text { TOC removal }(\%)=\left(1-\frac{\mathrm{TOC}_{\mathrm{t}}}{\mathrm{TOC}_{0}}\right) \times 100
$$

Where, $\mathrm{TOC}_{\mathrm{t}}$ concentration at any time $\mathrm{t}$, and $\mathrm{TOC}_{0}$ is initial concentration at time zero.

Liquid chromatography-mass spectroscopy (LC-MS) analysis of the reacted 4-NP samples was made to identify the intermediate products over the mass range of 40-400 amu. (model: Q-TOF micro waters, Waters, USA). The reacted sample was analyzed for determination of intermediate products using negative mode electrospray ionization (ESI) technique.

\section{Results and Discussion}

\subsection{Effect of $\mathrm{pH}$}

The $\mathrm{pH}$ value of solution influenced the generation of hydroxyl radicals and thus the oxidation efficiency of 4-NP. It is known that the Fenton's reaction is active in acidic medium. Thus, the effect of $\mathrm{pH}$ on the degradation of 4-NP was carried out by varying the $\mathrm{pH}$ in the range 1 to 5 at the initial reaction conditions of $\mathrm{H}_{2} \mathrm{O}_{2}$ concentration of $2 \mathrm{mM}, \mathrm{Fe}^{2+}$ concentration of $0.2 \mathrm{mM}$ at $30^{\circ} \mathrm{C}$ and $40 \mathrm{~min}$ of reaction time. The effect of $\mathrm{pH}$ on oxidation of 4-NP i.e. degradation efficiency, COD removal (\%) and TOC removal (\%) is presented in Fig. 1.

It is observed that the degradation (\%) of 4-NP increased from $28 \%$ to $84 \%$ with an increase in $\mathrm{pH}$ from 1 to 3 and thereafter it decreased to $65 \%$ with an increase in $\mathrm{pH}$ from 3 to 5 . Similarly, the COD and TOC removal (\%) of 4-NP has increased from 16\% to $42 \%$ and $23 \%$ to $53 \%$, respectively with increase in $\mathrm{pH}$ from 1 to 3 and it decreased to $32 \%$ and $40 \%$, respectively with further increase in $\mathrm{pH}$ from 3 to 5 . The maximum degradation of $84 \%$ was obtained for 4-NP at $\mathrm{pH}$ 3. The COD removal (\%) and TOC removal (\%) for $4-\mathrm{NP}$, at $3 \mathrm{pH}$ were $42 \%$ and $53 \%$ respectively. Therefore, the optimum $\mathrm{pH}$ for the degradation along with mineralization of 4-NP was 3. Below pH 3, the degradation (\%) of 4-NP 


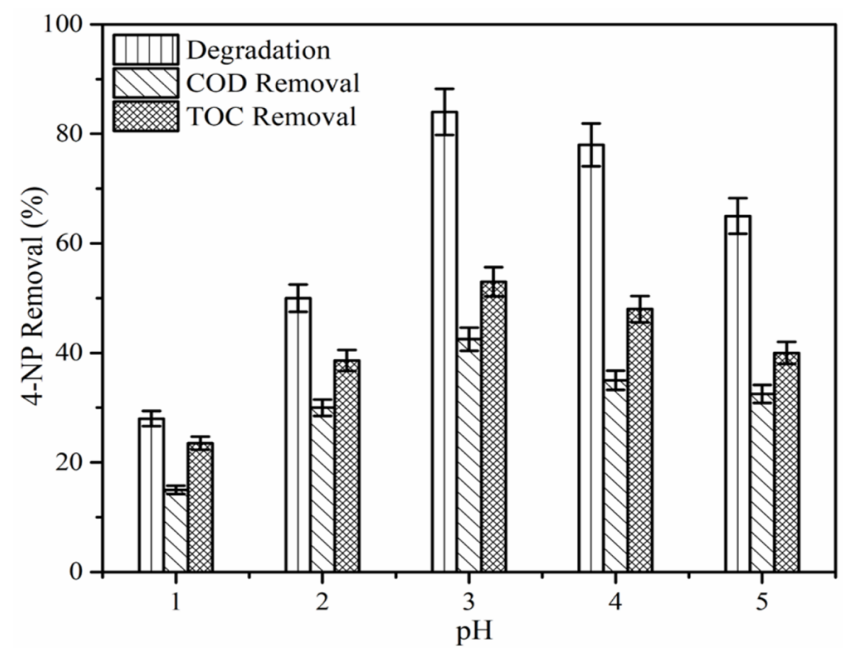

Fig. 1. Effect of $\mathrm{pH}$ on the degradation of $100 \mathrm{mg} / \mathrm{L}$ of 4-NP at reaction conditions: $\left[\mathrm{H}_{2} \mathrm{O}_{2}\right]=2 \mathrm{mM},\left[\mathrm{Fe}^{2+}\right]=0.2 \mathrm{mM}$ and time $=$ $40 \mathrm{~min}$.

was low because very less ${ }^{\circ} \mathrm{OH}$ radicals were produced as hydrogen peroxide was not decomposed by $\mathrm{Fe}^{2+}$ ions due to the stable oxygen concentration [29]. At very low $\mathrm{pH}, \mathrm{H}^{+}$ion acts as ${ }^{\circ} \mathrm{OH}$ radical scavengers according to Eq. (4) [30].

$$
\mathrm{HO}^{\bullet}+\mathrm{H}^{+}+\mathrm{e}^{-} \rightarrow \mathrm{H}_{2} \mathrm{O}
$$

Inhibition of ${ }^{\circ} \mathrm{OH}$ radical generation at low $\mathrm{pH}$ is due to the formation of complex species $\left[\mathrm{Fe}\left(\mathrm{H}_{2} \mathrm{O}\right) 6\right]^{2+}$ which reacts very slowly with hydrogen peroxide. In addition, the $\mathrm{H}_{2} \mathrm{O}_{2}$ gets solvated in the presence of high concentration of $\mathrm{H}^{+}$ions at low $\mathrm{pH}$ to form stable oxonium ion $\left[\mathrm{H}_{3} \mathrm{O}_{2}\right]^{+}$. The oxonium ion makes $\mathrm{H}_{2} \mathrm{O}_{2}$ electrophilic to enhance its stability, thus reducing the reactivity with $\mathrm{Fe}^{2+}$ ions [31]. At $\mathrm{pH} 4$ and 5, due to the formation of ferrous and ferric oxy-hydroxides complexes, lesser amount of the ${ }^{\circ} \mathrm{OH}$ radicals were generated which might have resulted in lower degradation and mineralization of 4-NP [11]. De Luis et al. [32] study has also observed maximum degradation of phenols (ortho, meta and para-cresol) at pH 3 using a homogeneous Fenton oxidation process. Meric et al. [22] achieved COD removal of 78.6\% for Reactive Black 5 (RB5) dye at $\mathrm{pH} 3$.

\subsection{Effect of Reaction Time}

The degradation of 4-NP was analyzed by varying the reaction time from $4 \mathrm{~min}$ to $1 \mathrm{~h}$ and is shown in Fig. 2. The reaction time needed for the degradation of 4-NP will depend on various parameters like $\mathrm{pH}$, initial concentration of 4-NP, concentrations of ferrous ions and $\mathrm{H}_{2} \mathrm{O}_{2}$. For the initial reaction of $100 \mathrm{mg} / \mathrm{L}$ of $4-\mathrm{NP}, 2$ $\mathrm{mM}$ of $\mathrm{H}_{2} \mathrm{O}_{2}, 0.2 \mathrm{mM}$ of $\mathrm{Fe}^{2+}$ concentration and at $\mathrm{pH} 3$, it is observed that the degradation of 4-NP increased linearly up to 8 min of reaction time and then followed the non-linear increase up to $40 \mathrm{~min}$. The degradation of $4-\mathrm{NP}$ was increased from $35 \%$ to $84 \%$ with increase in reaction time from $4 \mathrm{~min}$ to $40 \mathrm{~min}$ and thereafter no further degradation of 4-NP has been noticed. Therefore, the optimum reaction time for the degradation of 4-NP was observed to be $40 \mathrm{~min}$ for further studies.

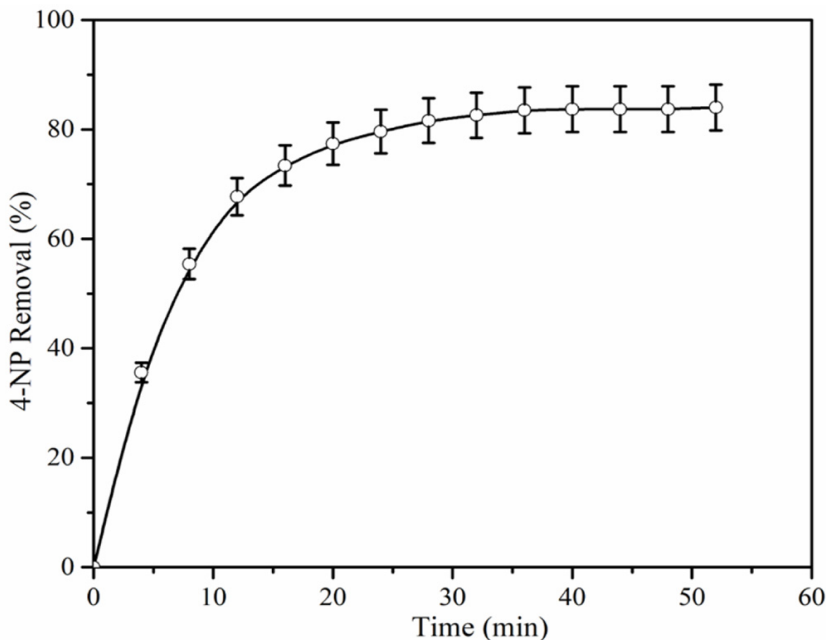

Fig. 2. Effect of reaction time on the degradation of 4-NP; Conditions: $[4-\mathrm{NP}]=100 \mathrm{mg} / \mathrm{L},\left[\mathrm{H}_{2} \mathrm{O}_{2}\right]=2 \mathrm{mM},\left[\mathrm{Fe}^{2+}\right]=0.2 \mathrm{mM}, \mathrm{pH}$ $=3$ and time $60 \mathrm{~min}$.

\subsection{Effect of $\mathrm{H}_{2} \mathrm{O}_{2}$ Concentration}

The dosage of $\mathrm{H}_{2} \mathrm{O}_{2}$ is an important parameter as it affects the generation of $\mathrm{OH}$ radicals. The $\mathrm{H}_{2} \mathrm{O}_{2}$ concentration was varied from $1 \mathrm{mM}$ to $5 \mathrm{mM}$ to study the mineralization and degradation of 4-NP. The effect of $\mathrm{H}_{2} \mathrm{O}_{2}$ on the degradation, COD removal and TOC removal of 4-NP is shown in Fig. 3. It is observed that the degradation, COD removal and TOC removal of 4-NP increased with increase in concentration of $\mathrm{H}_{2} \mathrm{O}_{2}$ from $1 \mathrm{mM}$ to $4 \mathrm{mM}$ and thereafter decreased. The $\mathrm{H}_{2} \mathrm{O}_{2}$ concentration of $4 \mathrm{mM}$, degradation, COD removal (\%) and TOC removal (\%) of 4-NP were obtained to be $93.6,50 \%$ and $60.3 \%$, respectively. Increased concentration of $\mathrm{H}_{2} \mathrm{O}_{2}$ from $1 \mathrm{mM}$ to $4 \mathrm{mM}$ have resulted in more ${ }^{\circ} \mathrm{OH}$ radicals, which might have increased the degradation and mineralization of 4-NP. Further at higher $\mathrm{H}_{2} \mathrm{O}_{2}$ dosage, i.e. $5 \mathrm{mM}$ the decrease in degradation, COD removal and TOC removal of 4-NP might

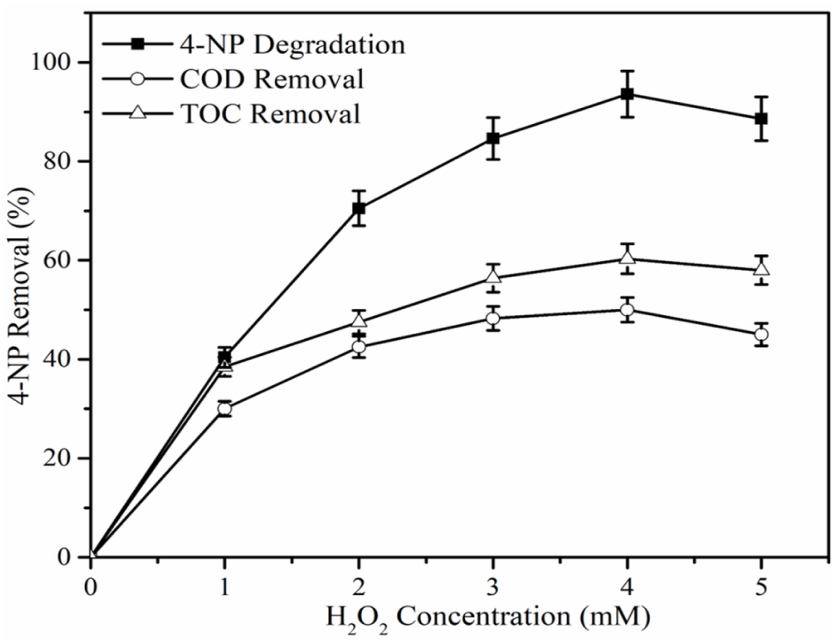

Fig. 3. Effect of $\mathrm{H}_{2} \mathrm{O}_{2}$ concentration on the degradation of 4-NP, COD removal and TOC removal; Conditions: [4-NP] $=100 \mathrm{mg} / \mathrm{L}$, $\left[\mathrm{Fe}^{2+}\right]=0.2 \mathrm{mM}, \mathrm{pH}=3$, time $=40 \mathrm{~min}$. 
be due to the scavenging of generated ${ }^{\circ} \mathrm{OH}$ radicals i.e. the ${ }^{\circ} \mathrm{OH}$ radicals may react with $\mathrm{H}_{2} \mathrm{O}_{2}$ to generate $\mathrm{HO}_{2}{ }^{\circ}$ radicals and which are less reactive than ${ }^{\circ} \mathrm{OH}$ radicals $[18,33]$.

$$
\mathrm{H}_{2} \mathrm{O}_{2}+\mathrm{HO}^{\bullet} \rightarrow \mathrm{HO}_{2}^{\bullet}+\mathrm{H}_{2} \mathrm{O}
$$

Also the unused portion of $\mathrm{H}_{2} \mathrm{O}_{2}$ during the Fenton process contributed to COD and hence the excess amount was not recommended [34, 35].

\subsection{Effect of $\mathrm{Fe}^{2+}$ Ions Concentration}

It is utmost important to analyze the optimum loading of $\mathrm{Fe}^{2+}$ ions to mineralize and degrade 4-NP, because at low $\mathrm{Fe}^{2+}$ ion concentrations, the degradation and mineralization of 4-NP are less due to insufficient amount of $\mathrm{Fe}^{2+}$ ions. But higher quantities of $\mathrm{Fe}^{2+}$ ions lead to an unutilized quantity of iron salt, which further contributes to increase the total dissolved solids content in the solution [36, 37]. The range of $\mathrm{Fe}^{2+}$ ion concentration was selected by performing initial experiments. The concentration of $\mathrm{Fe}^{2+}$ ions was varied from $0.05 \mathrm{mM}$ to $0.5 \mathrm{mM}$ and keeping the rest of the parameters constant and the results are shown in Fig. 4. It was found that the degradation and mineralization (TOC and COD removal) rate increased with an increase in the $\mathrm{Fe}^{2+}$ ion concentration up to $0.2 \mathrm{mM}$ of aqueous solution and after that the degradation and mineralization rate decreased (Fig. 4). The maximum degradation of $4-\mathrm{NP}(93.6 \%)$ was observed at $\mathrm{Fe}^{2+}$ ion concentration of 0.2 $\mathrm{mM}$.

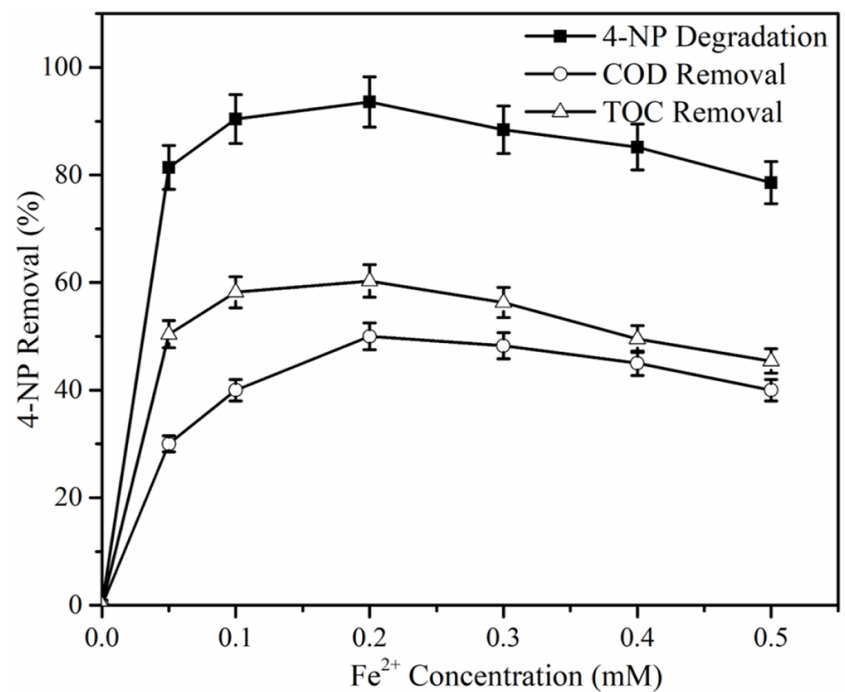

Fig. 4. Effect of ferrous ions concentration on the degradation of 4-NP, COD removal and TOC removal; Conditions: $[4-\mathrm{NP}]=100$ $\mathrm{mg} / \mathrm{L},\left[\mathrm{H}_{2} \mathrm{O}_{2}\right]=4 \mathrm{mM}, \mathrm{pH}=3$, time $40 \mathrm{~min}$.

The mineralization i.e. COD removal and TOC removal increased from $30 \%$ to $50 \%$ and $50.4 \%$ to $60.3 \%$, respectively, with increase in $\mathrm{Fe}^{2+}$ ion concentration from $0.05 \mathrm{mM}$ to $0.2 \mathrm{mM}$. The higher dosage of $\mathrm{Fe}^{2+}$ ions $(>0.2 \mathrm{mM})$ may result to scavenging effect with ${ }^{\circ} \mathrm{OH}$ radicals present in solution as per the following reaction [22]:

$$
\begin{gathered}
\mathrm{Fe}^{2+}+\mathrm{HO}^{\bullet} \rightarrow \mathrm{Fe}^{3+}+\mathrm{OH} \\
\mathrm{H}_{2} \mathrm{O}_{2}+\mathrm{HO}^{-} \rightarrow \mathrm{HO}_{2}^{\bullet}+\mathrm{H}_{2} \mathrm{O}^{+}
\end{gathered}
$$

\subsection{Reaction Mechanism Showing the Degradation Pathways of $4-\mathrm{NP}$}

The $\mathrm{OH}$ radicals were generated during the reaction between $\mathrm{Fe}^{2+}$ ions and hydrogen peroxide. The ${ }^{\circ} \mathrm{OH}$ radicals reacted with 4-NP compound and led to the formation of intermediate products. The reaction products of the degraded 4-NP were identified using LC-MS spectra at a retention time of $3.542 \mathrm{~min}$ (Fig. 5). 3,4-dihydroxynitrobenzene, 1,2,4 trihydroxylbenzene, 1,2-dihydroxyaminophenol, 4-aminophenol, Hydroquinone, p-benzoquinone, 3,4,5-tridydroxynitrobenzene, 1,2,6-trihydroxy-4-aminophenol and acetic acid were identified as the some of the intermediate products by the following reactions:

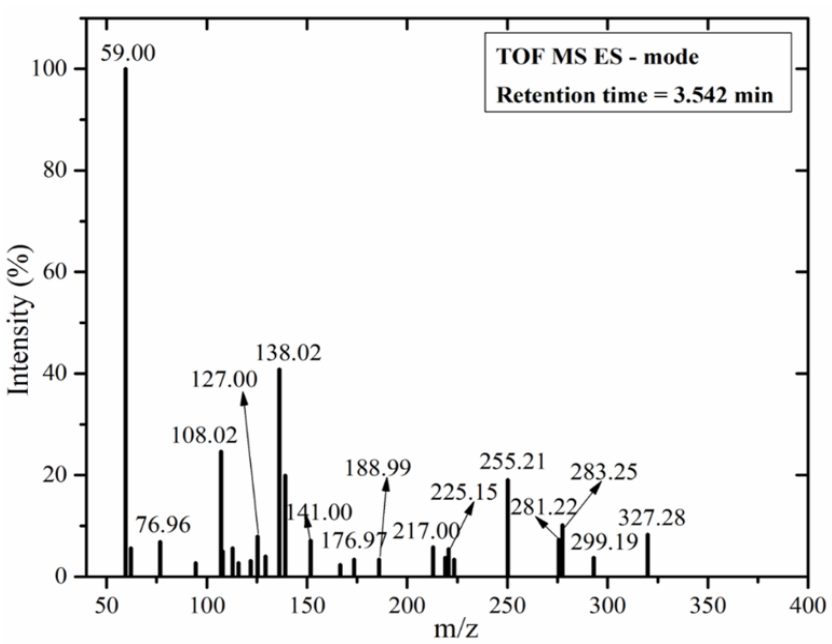

Fig. 5. LC-MS spectra analysis after degradation of 4-NP at optimized reaction conditions: $4 \mathrm{mM}$ of $\mathrm{H}_{2} \mathrm{O}_{2}$ concentration, $0.2 \mathrm{mM}$ of $\mathrm{Fe}^{2+}$ concentration, 40 min reaction time.

$$
\begin{aligned}
\mathrm{C}_{6} \mathrm{H}_{5} \mathrm{NO}_{3}+\mathrm{HO}^{\bullet} \rightarrow & \mathrm{C}_{6} \mathrm{H}_{5} \mathrm{NO}_{4}+\mathrm{H}^{+} \\
\text {4-Nitrophenenol } & \text { 3,4-dihydroxynitrobenzene } \\
\mathrm{C}_{6} \mathrm{H}_{5} \mathrm{NO}_{4}+\mathrm{HO}^{\bullet} \rightarrow & \mathrm{C}_{6} \mathrm{H}_{6} \mathrm{NO}_{3}+\mathrm{NO}_{2} \\
& \text { 1,2,4-trihydroxylbenzene } \\
\mathrm{C}_{6} \mathrm{H}_{5} \mathrm{NO}_{3}+2 \mathrm{H}^{+} \rightarrow & \mathrm{C}_{6} \mathrm{H}_{7} \mathrm{NO}+\mathrm{O}_{2}+\mathrm{e}^{-} \\
& \text {-aminophenol } \\
\mathrm{C}_{6} \mathrm{H}_{5} \mathrm{NO}_{4}+\mathrm{H}^{+} \rightarrow & \mathrm{C}_{6} \mathrm{H}_{7} \mathrm{NO}_{2}+\mathrm{e}^{-} \\
& \text {1,2-dihydroxyaminophenol } \\
\mathrm{C}_{6} \mathrm{H}_{7} \mathrm{NO}+\mathrm{HO}^{\bullet} \rightarrow & \mathrm{C}_{6} \mathrm{H}_{8} \mathrm{NO}^{-} \\
& 4 \text {-aminophenol } \\
\mathrm{C}_{6} \mathrm{H}_{8} \mathrm{NO}+\mathrm{HO}^{\bullet} \rightarrow & \mathrm{C}_{6} \mathrm{H}_{6} \mathrm{NO}_{2}+\mathrm{NH}_{3} \\
& \text { Hydroquinone }
\end{aligned}
$$


Table 2. The Various Intermediate Products Formed After The Degradation of 4-NP

Intermediate name
4-nitrobenzene-1,2-diol
(3,4-dihydroxynitrobenzene

Benzene-1,2,4-triol

(1,2,4 trihydroxylbenzene)

4-aminobenzene-1,2-diol

(1,2-dihydroxyaminophenol)

4-aminophenol

$\mathrm{C}_{6} \mathrm{H}_{7} \mathrm{NO}$

Hydroquinone

p-benzoquinone

1,4- benzoquinone

5-nitrobenzene-1,2,3-triol

(3,4,5-tridydroxynitrobenzene)

5-aminobenzene-1,2,3-triol

(1,2,6-trihydroxy-4-aminophenol)

Acetic acid

$\mathrm{C}_{6} \mathrm{H}_{5} \mathrm{NO}_{4}$

$\mathrm{C}_{6} \mathrm{H}_{6} \mathrm{O}_{3}$

$\mathrm{C}_{6} \mathrm{H}_{7} \mathrm{NO}_{2}$

$\mathrm{C}_{6} \mathrm{H}_{6} \mathrm{O}_{2}$

$\mathrm{C}_{6} \mathrm{H}_{4} \mathrm{O}_{2}$

$\mathrm{C}_{6} \mathrm{H}_{5} \mathrm{NO}_{5}$

$\mathrm{C}_{6} \mathrm{H}_{7} \mathrm{NO}_{3}$

$\mathrm{C}_{2} \mathrm{H}_{4} \mathrm{O}_{2}$

\section{Chemical formula}

$$
\mathrm{C}_{6} \mathrm{H}_{5} \mathrm{NO}_{4}+\mathrm{HO}^{\bullet} \rightarrow \mathrm{C}_{6} \mathrm{H}_{5} \mathrm{NO}_{5}+\mathrm{H}^{+}
$$

(3,4,5-tridydroxynitrobenzene)

$$
\mathrm{C}_{6} \mathrm{H}_{5} \mathrm{NO}_{5}+2 \mathrm{H}^{+} \rightarrow \mathrm{C}_{6} \mathrm{H}_{7} \mathrm{NO}_{3}+\mathrm{O}_{2}
$$

1,2,6-trihydroxy-4-aminophenol

\section{Structure}

Molecular weight

$\mathrm{OH}$

$\underbrace{\mathrm{OH}}_{\mathrm{NO}_{2}}$

OH

126

(NH

126

(1)

109<smiles>Oc1ccc(O)cc1</smiles>

110<smiles>O=C1C=CC(=O)C=C1</smiles>

108<smiles>O=[N+]([O-])c1cc(O)c(O)c(O)c1</smiles><smiles>Nc1cc(O)c(O)c(O)c1</smiles>

$\mathrm{H}_{3} \mathrm{C}-\mathrm{COOH}$

60

$$
\begin{aligned}
& \mathrm{C}_{6} \mathrm{H}_{4} \mathrm{O}_{2}+2 \mathrm{HO}^{\bullet} \rightarrow \mathrm{C}_{6} \mathrm{H}_{4} \mathrm{O}_{4}+2 \mathrm{H}^{+} \\
& \mathrm{C}_{2} \mathrm{H}_{4} \mathrm{O}_{2}+8 \mathrm{HO}^{\bullet} \rightarrow 2 \mathrm{CO}_{2}+2 \mathrm{H}_{2} \mathrm{O} \\
& \text { Acetic acid }
\end{aligned}
$$

Details of identified intermediate products formed after the degradation of 4-NP are given in Table 2 .

3,4-dihydroxynitrobenzene, 1,2,4-trihydroxylbenzene, 3,4,5 trihydroxynitrobenzene, hydroquinone, p-benzoquinone, $\mathrm{CO}_{2}$ and 
Table 3. Comparison of Present Study for The Degradation of 4-NP with Previous Studies

\begin{tabular}{|c|c|c|c|c|c|c|c|}
\hline Reference & Pollutant & $\begin{array}{l}\text { Initial operating } \\
\text { conditions }\end{array}$ & $\begin{array}{l}\text { Degradation } \\
\text { (\%) }\end{array}$ & $\begin{array}{c}\text { COD } \\
\text { removal } \\
(\%)\end{array}$ & $\begin{array}{c}\text { TOC } \\
\text { removal } \\
(\%)\end{array}$ & $\begin{array}{c}\text { DOC } \\
\text { removal } \\
(\%)\end{array}$ & Kinetic study \\
\hline $\begin{array}{l}\text { Ma et al., } \\
2000[18]\end{array}$ & 4-Nitrophenol & $\begin{array}{c}{[4-\mathrm{NP}]_{0}=1 \mathrm{mM}} \\
{\left[\mathrm{H}_{2} \mathrm{O}_{2}\right]=1-10 \mathrm{mM}} \\
{\left[\mathrm{Fe}^{2+}\right]=1-10 \mathrm{mg} / \mathrm{L}} \\
\mathrm{pH}=3\end{array}$ & 99 & - & - & 30.6 & $\begin{array}{l}\text { 4-NP degradation profiles fit- } \\
\text { ted well into a pseudo first- } \\
\text { order kinetic equation. }\end{array}$ \\
\hline $\begin{array}{l}\text { Kavitha and } \\
\text { Palanivelu, } \\
2005[20]\end{array}$ & $\begin{array}{l}\text { 2-nitrophenol (2-NP), } \\
\text { 4-nitrophenol (4-NP), } \\
\text { 2,4-dinitrophenol (DNP), } \\
\text { 2,4,6- trinitrophenol (TNP) }\end{array}$ & $\begin{array}{c}{[2-\mathrm{NP} / 4-\mathrm{NP}]_{0}=1.43 \mathrm{mM}} \\
{\left[\mathrm{H}_{2} \mathrm{O}_{2}\right]=17.3 \mathrm{mM}} \\
{\left[\mathrm{Fe}^{2+}\right]=0.45 \mathrm{mM}} \\
{[\mathrm{DNP}]=1.08 \mathrm{mM}} \\
{[\mathrm{TNP}]=0.87 \mathrm{mM}} \\
\mathrm{pH}=3\end{array}$ & - & - & - & 32 & $\begin{array}{l}\text { Degradation of NPs obeys a } \\
\text { pseudo-first-order kinetics. } \\
\text { Treatment efficiency for the } \\
\text { NPs followed the sequence: } \\
\text { NP > DNP > TNP. }\end{array}$ \\
\hline $\begin{array}{l}\text { Present } \\
\text { Study }\end{array}$ & 4-NP & $\begin{array}{c}{[4-\mathrm{NP}]_{0}=0.72 \mathrm{mM}} \\
{\left[\mathrm{H}_{2} \mathrm{O}_{2}\right]=1-5 \mathrm{mM}} \\
{\left[\mathrm{Fe}^{2+}\right]=0.05-0.5 \mathrm{mM}} \\
\mathrm{pH}=3\end{array}$ & 93.6 & 50 & 60.3 & - & $\begin{array}{l}\text { The degradation of 4-NP fol- } \\
\text { lowed second order kinetics. }\end{array}$ \\
\hline
\end{tabular}

$\mathrm{H}_{2} \mathrm{O}$ were identified as the intermediate products by Ziang et al. [38]. Daneshvar et al. [39] study has identified 3,4-dihydroxynitrobenzene, 1,2,4 trihydroxylbenzene, hydroquinone as the intermediate products using photo-oxidative degradation of 4-NP. Jiang et al. [40] carried out electrochemical degradation of 4-NP and resulted in the formation of hydroquinone, p-benzoquinone, 4-aminophenol as the intermediate products. Sun and Lemley [41], Zhao et al. [42] and Minz et al. [43] studies have reported the formation of 3,4-dihydroxynitrobenzene, 1,2,4-trihydroxylbenzene, hydroquinone, p-benzoquinone, as the intermediate products after degradation of 4-NP. Some of the residual fragments against molecular weights 76.96, 188.99, 217.0, 225.15, 255.21, 281.22, 283.25, 299.19 and 327.28 remained unidentified may be due to the complexity of their formation in the solution phase.

\subsection{Kinetic Study}

The kinetics of the reaction helps to study the factors which influence the rate of reaction like reactant concentration, oxidant concentration and composition of the reaction mixture [44] and provides useful information about the mechanism and rate of chemical reaction. Kinetic study for the degradation of 4-NP was done as a function of time at optimum reaction conditions, i.e. initial 4-NP concentration $100 \mathrm{mg} / \mathrm{L},\left[\mathrm{H}_{2} \mathrm{O}_{2}\right]: 4 \mathrm{mM},\left[\mathrm{Fe}^{2+}\right]: 0.2 \mathrm{mM}$ and $\mathrm{pH}$ 3. The degradation data of $4-\mathrm{NP}$ was analyzed for $1^{\text {st }}$ order and $2^{\text {nd }}$ order rate expressions as:

First order kinetics

$$
\ln \frac{\mathrm{C}_{0}}{\mathrm{C}_{\mathrm{t}}}=\mathrm{kt}
$$

Second order kinetics

$$
\frac{1}{C_{t}}=\frac{1}{C_{o}}+k^{\prime} t
$$

Where, $\mathrm{C}_{0}$ is the initial concentration of $4-\mathrm{NP}$ and $\mathrm{C}_{t}$ is the concentration of 4-NP at any time t, $\mathrm{k}$ and $\mathrm{k}$ represents the rate constants of first and second order reactions respectively.

Kinetic rate constant for the degradation of 4-NP for $1^{\text {st }}$ order and $2^{\text {nd }}$ order rate expression are $0.0829 \mathrm{~min}^{-1}$ and $0.0037 \mathrm{~L} \mathrm{mg}^{-1}$ $\mathrm{min}^{-1}$. The higher value of the regression coefficient (0.974) for $2^{\text {nd }}$ order reaction as compared to $1^{\text {st }}$ order reaction (0.853) shows that the degradation of 4 -NP obeys $2^{\text {nd }}$ order reaction rate with rate constant of $0.0037 \mathrm{~L} \mathrm{mg}^{-1} \mathrm{~min}^{-1}$. Ghosh et al. [26] also observed second order rate for the degradation of 4-chlorophenol (4-CP) and nitrobenzene using Fenton reagent. The degradation of 2,6-dimethyl aniline using ${ }^{\circ} \mathrm{OH}$ radicals also showed that the data was well fitted to second order kinetic model [45].

\subsection{Comparison with Earlier Studies}

A comparison of homogeneous Fenton process for the degradation of 4-NP for the present and available reported studies has been made and is shown in Table 3. Ma et al. [21] achieved 99\% degradation of 4-NP using $5 \mathrm{mM}$ of $\mathrm{H}_{2} \mathrm{O}_{2}$ concentration, $5 \mathrm{mg} / \mathrm{L}$ of $\mathrm{Fe}^{2+}$ at $\mathrm{pH} 3$ in $2 \mathrm{~h}$. Also, the dissolved organic carbon (DOC) removal efficiency was $30.6 \%$, i.e. only one-third of 4-NP was mineralized. Another study on the degradation of nitrophenols: 2-nitrophenol (2-NP), 4-nitrophenol (4-NP), 2,4-dinitrophenol (DNP) and 2,4,6-trinitrophenol (TNP), the maximum mineralization (DOC) for mono-nitrophenols was 32\% [23]. However, in the present study, 93.6\% degradation of 4-NP was achieved with 50\% COD removal and $60.3 \%$ TOC removal efficiency in the short reaction period of $40 \mathrm{~min}$. The mineralization efficiency achieved is higher than the previous studies.

\section{Conclusions}

The mineralization studies on 4-NP along with degradation have been made using homogeneous Fenton's oxidation.

The present study revealed that homogeneous Fenton's oxidation process can be used for the mineralization and degradation 
of 4-NP. The optimum reaction conditions for 4-NP degradation and mineralization are observed at $\mathrm{pH} 3, \mathrm{H}_{2} \mathrm{O}_{2}$ concentration of $4 \mathrm{mM}, \mathrm{Fe}^{2+}$ concentration of $0.2 \mathrm{mM}$ in $40 \mathrm{~min}$ of reaction time. At optimal condition, 93.6\% of 4-NP were degraded within 40 min with COD removal (\%) and TOC removal (\%) of $50 \%$ and $60.3 \%$, respectively. The kinetic study revealed the degradation of 4-NP by second order kinetics with rate constant of 0.0037 $\mathrm{L} \mathrm{mg}^{-1} \mathrm{~min}^{-1}$ and correlation coefficient 0.974 . The higher mineralization efficiency of 4-NP (50\% COD removal and 60.3\% TOC removal) has been observed in the present study as compared to the previous reported studies. Based upon the LC-MS spectra analysis 3,4-dihydroxynitrobenzene, 1,2-dihydroxyaminophenol, 1,2,6-trihydroxy-4-aminophenol, 3,4,5-trihydroxynitrobenze, 4-aminophenol, hydroquinone, p-benzoquinone, acetic acid etc. have been identified as the intermediate products. The present study indicated that the Fenton process was a feasible method to treat acidic wastewaters. This method could also be used in combination with other AOPs for better results.

\section{Acknowledgment}

The authors thankfully acknowledge the facilities extended by sophisticated analytical instrumentation facility of Panjab University, Chandigarh, India and Dr. B. R. Ambedkar National Institute of Technology, Jalandhar, India.

\section{Author Contributions}

S.M. (Ph.D student) conducted all the experimental work under the joint supervision of Dr. R.G. (Associate Professor) and Dr. S.G. (Associate Professor).

\section{References}

1. Zhao B, Mele G, Pio I, Li J, Palmisano L, Vasapoll G. Degradation of 4-nitrophenol (4-NP) using $\mathrm{Fe}^{-\mathrm{TiO}_{2}}$ as a heterogeneous photo-Fenton catalyst. J. Hazard. Mater. 2010;176:569-574.

2. Sun S-P, Lemley T. p-Nitrophenol degradation by a heterogeneous Fenton-like reaction on nano-magnetite: Process optimization, kinetics, and degradation pathways. J. Mol. Catal. A Chem. 2011;349:71-79.

3. Liotta LF, Gruttadauria M, Carlo GD, Perrini G, Librando V. Heterogeneous catalytic degradation of phenolic substrates: Catalysts activity. J. Hazard. Mater. 2009;162:588-606.

4. Fathi Z, Keshmirizadeh E. Use of Fenton Reagent as Advanced Oxidative Process for Removal of Basic and Acid Red Dyes from Aqueous Solutions. J. Appl. Chem. Res. 2015;9:7-19.

5. Song Y, Xiao L. Comparison treatment of various chlorophenols by electro-Fenton method: relationship between chlorine content and degradation. J. Hazard. Mater. 2005;118:85-92.

6. Kang N, Lee DS, Yoon J. Kinetic modeling of Fenton oxidation of phenol and monochlorophenols. Chemosphere 2002;47:915-924.

7. Hong APK, Zeng Y. Degradation of pentachlorophenol by ozonation and biodegradability of intermediates. Water Res. 2002;36:
4243-4254.

8. Sauleda R, Brillas E. Mineralization of aniline and 4-chlorophenol in acid solution by ozonation catalyzed with $\mathrm{Fe}^{2+}$ and UVA light. Appl. Catal. 2001;29:135-145.

9. Ho TFL, Bolton JR. Toxicity changes during the UV treatment of pentachlorophenol in dilute aqueous solution. Water Res. 1998;32:489-497.

10. Chang MW, Chen TS, Chern JM. Initial degradation rate of p-nitrophenol in aqueous solution by Fenton reaction. Ind. Eng. Chem. Res. 2008;47:8533-8541.

11. Ghaly MY, Härtel G, Mayer R, Haseneder R. Photochemical oxidation of p-chlorophenol by $\mathrm{UV} / \mathrm{H}_{2} \mathrm{O}_{2}$ and photo-Fenton process. A comparative study. Waste Manag. 2001;21:41-47.

12. Subramonian W, Wu TY, Chai S-P. Photocatalytic degradation of industrial pulp and paper mill effluent using synthesized magnetic $\mathrm{Fe}_{2} \mathrm{O}_{3}-\mathrm{TiO}_{2}$ : Treatment efficiency and characterizations of reused photocatalyst. J. Environ. Manag. 2017;187: 298-310.

13. Teh CY, Wu TY, Juan JC. An application of ultrasound technology in synthesis of titania-based photocatalyst for degrading pollutant. Chem. Eng. J. 2017;317:586-612.

14. Duan F, Yang Y, Li Y, Cao H, Wang Y, Zhang Y. Heterogeneous Fenton-like degradation of 4-chlorophenol using iron/ordered mesoporous carbon catalyst. J. Environ. Sci. 2014;26:1171-1179.

15. Palaniandy P, AHBA SF. A review on the Fenton process for wastewater treatment. J. Innov. Eng. 2014;2(3):4.

16. Ertugay N, Acar FN. Removal of COD and color from Direct Blue 71 azo dye wastewater by Fenton's oxidation: Kinetic study. Arab. J. Chem. 2017;10:S1158-S1163.

17. Giri AS, Golder AK. Ciprofloxacin degradation from aqueous solution by Fenton oxidation: reaction kinetics and degradation mechanisms. RSC Advances 2014;4:6738-6745.

18. Barbusinski K. Toxicity of industrial wastewater treated by Fenton's reagent”. Pol. J. Environ. Stud. 2005;14:11-16.

19. Barbeni M, Minero C, Pelizzetti E, Borgarello E, Serpone N. Chemical degradation of chlorophenols with Fenton's reagent $\left(\mathrm{Fe}^{2+}+\mathrm{H}_{2} \mathrm{O}_{2}\right)$. Chemosphere 1987;16:2225-2237.

20. Kwon BG, Lee DS, Kang N, Yoon J. Characteristics of p-chlorophenol oxidation by Fenton's reagent. Water Res. 1999;33: 2110-2118.

21. Ma YS, Huang ST, Lin JG. Degradation of 4-nitrophenol using the Fenton process. Water Sci. Technol. 2000;42:155-160.

22. Meriç S, Kaptan D, Ölmez T. Color and COD removal from wastewater containing Reactive Black 5 using Fenton's oxidation process. Chemosphere 2004;54:435-441.

23. Kavitha V, Palanivelu K. Degradation of nitrophenols by Fenton and photo-Fenton processes. J. Photochem. Photobiol. A 2005; 170:83-95.

24. La Nafie N. Application of Fenton's reagent on remediation of Polycyclic Aromatic Hydrocarbons (PAHs) in spiked soil. Indones. J. Chem. 2010;7:208-213.

25. Khamaruddin, PF, Bustam MA, Omar AA. Using Fenton's reagents for the degradation of disopropanolamine: effect of temperature and $\mathrm{pH}$ ". In International Conference on Environment and Industrial Innovation. 2011;12:12-17.

26. Ghosh P, Kelapure P, Samanta AN, Ray S. Determination of reaction rate constant for $\mathrm{p}$-chlorophenol and nitrobenzene re- 
acting with $\mathrm{OH}$ during oxidation by $\mathrm{Fe}(\mathrm{II}) / \mathrm{H}_{2} \mathrm{O}_{2}$ system. Int. J. Chem. Tech. Res. 2012;4:116-123.

27. El Haddad M, Regti A, Laamari MR, Mamouni R, Saffaj N. Use of Fenton reagent as advanced oxidative process for removing textile dyes from aqueous solutions. J. Mater. Environ. Sci. 2014;5:667-674.

28. Clesceri LS, Greenburg AE, Eaton AD. Standard methods for the examination of water and wastewater. $20^{\text {th }}$ ed. Washington, DC, American Public Health Association (APHA); 1999. Part 5220 .

29. Nidheesh PV, Gandhimathi R. Trends in electro-Fenton process for water and wastewater treatment: an overview. Desalination 2012;299:1-15.

30. Lucas MS and Peres JA. Decolorization of the azo dye Reactive Black 5 by Fenton and photo-Fenton oxidation. Dyes Pigm. 2006;71;236-244.

31. Dhahir SA, Al-Saade KA and Al-Jobouri IS. Degradation studies of Rhodamine $\mathrm{B}$ in the presence of $\mathrm{UV} / \mathrm{H}_{2} \mathrm{O}_{2} / \mathrm{Fe}^{2+}$. Int. J. Tech. Res. Appl. 2014;2:123-127.

32. De Luis A, Lombraña JI, Varona F, Menéndez A. Kinetic study and hydrogen peroxide consumption of phenolic compounds oxidation by Fenton's reagent. Korean J. Chem. Eng. 2009;26: 48-56.

33. Loow YL, Wu TY, Lim YS, Tan KA, Siow LF, Jahim JM, Mohammad AW. (2017). Improvement of xylose recovery from the stalks of oil palm fronds using inorganic salt and oxidative agent. Energy Convers. Manag. 2017;138:248-260.

34. Babuponnusami A, Muthukumar K. A review on Fenton and improvements to the Fenton process for wastewater treatment. J. Environ. Chem. Eng. 2014;2:557-572.

35. Lin SH, Lo CC. Fenton process for treatment of desizing wastewater. Water Res. 1997;31:2050-2056.

36. De AK, Dutta BK, Bhattacharjee S. Reaction kinetics for the degradation of phenol and chlorinated phenols using Fenton's reagent. Environ. Prog. Sustain. Energy 2005;25:64-71.

37. Zhou L, Hu J, Zhong H, Li X. Study of phenol removal using fluidized-bed Fenton process. Chem. Eng. Res. Des. 2012;90: 377-382.

38. Zhang W, Xiao X, An T, et al. Kinetics, degradation pathway and reaction mechanism of advanced oxidation of 4-nitrophenol in water by a UV/H2O2 process. J. Chem. Technol Biot. 2003;78:788-794.

39. Daneshvar N, Behnajady MA, Asghar YZ. Photo-oxidative degradation of 4-nitrophenol (4-NP) in $\mathrm{UV} / \mathrm{H}_{2} \mathrm{O}_{2}$ process: Influence of operational parameters and reaction mechanism. J. Hazard. Mater. 2007;139:275-279.

40. Jiang P, Zhou J, Zhang A, Zhong Y. Electrochemical degradation of p-nitrophenol with different processes. J. Environ. Sci. 2010;22:500-506.

41. Sun SP, Lemley AT. p-Nitrophenol degradation by a heterogeneous Fenton-like reaction on nano-magnetite: process optimization, kinetics, and degradation pathways. J. Mol. Catal. - A Chem. 2011;349:71-79.

42. Zhao S, Ma H, Wang M, Cao C, Yao S. Study on the role of hydroperoxyl radical in degradation of p-nitrophenol attacked by hydroxyl radical using photolytical technique. J. Photoch. Photobio. - A Chem. 2013;259:17-24.

43. Minz S, Garg S, Gupta R. Catalytic wet peroxide oxidation of 4-nitrophenol over $\mathrm{Al}-\mathrm{Fe}, \mathrm{Al}-\mathrm{Cu}$ and $\mathrm{Al}-\mathrm{Cu}-\mathrm{Fe}$ pillared clays. Indian Chem. Eng. 2018;60:16-36.

44. Sun JH, Sun SP, Fan MH, Guo HQ, Qiao LP, Sun RX. A kinetic study on the degradation of p-nitroaniline by Fenton oxidation process. J. Hazard. Mater. 2007;148:172-177.

45. Boonrattanakij N, Lu MC and Anotai J. Kinetics and mechanism of 2, 6-dimethyl-aniline degradation by hydroxyl radicals. $J$. Hazard. Mater. 2009;172:952-957. 